Supporting Information

\title{
Double Isothermal Amplification and CRISPR-Cas12a for Sensitive Detection of Citrinin
}

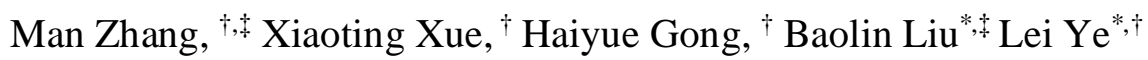

'Division of Pure and Applied Biochemistry, Department of Chemistry, Lund University, Box124, 22100 Lund, Sweden

${ }^{\star}$ School of Medical Instrument and Food Engineering, University of Shanghai for Science and Technology, Shanghai 200093, China

\section{*Corresponding authors:}

Baolin Liu, Email: blliuk@163.com; Lei Ye, Email: lei.ye@ tbiokem.lth.se 
dsDNA as activator

H0

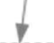

$\mathrm{H} 2$

3'-TGGAGTGAAGGCGCATACCTCTTTCCAATTATTCTGAATTGGAAAG'AGGTATGCGCCTTC:TGGAGTGAAGGCGCATACCTCTTTCCAATT-5 5'-ACCTCACTTCCGCGTATGGAGAAAGGTTAATAAGACTTAACCTTTC'TCCATACGCGGAAG'-3'

$\mathrm{H} 1$

Fig. S1 Complimentary sequences between $\mathrm{H} 0$ and $\mathrm{H} 1, \mathrm{H} 1$ and $\mathrm{H} 2$, and dsDNA in $\mathrm{H} 1-\mathrm{H} 2$ that activates CRISPR/Cas12a-gRNA. 


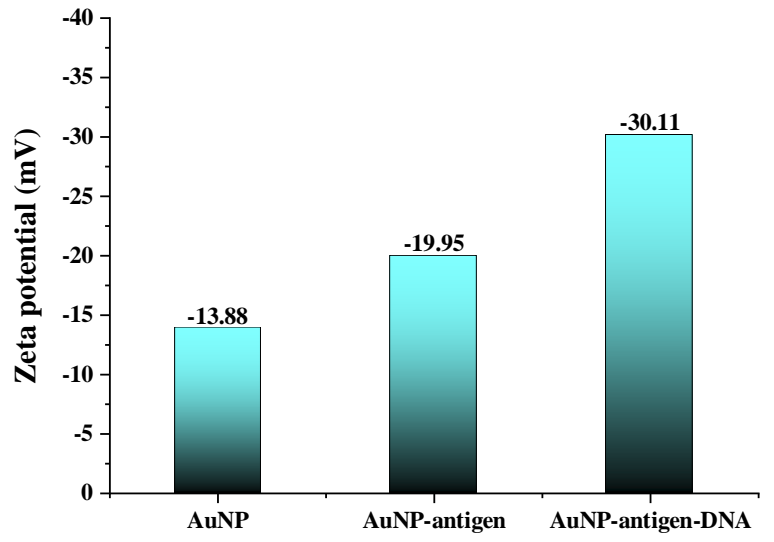

Fig. S2 Zeta potential of AuNPs, AuNP-antigen, AuNP-antigen-DNA probe. 


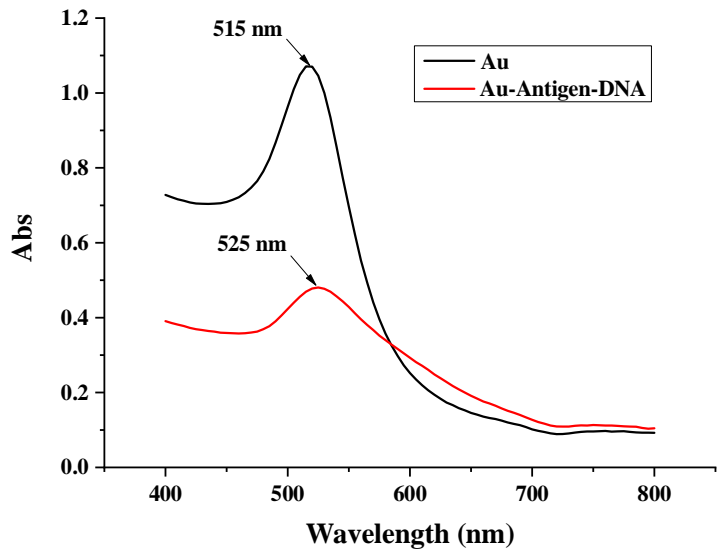

Fig. S3 UV-vis spectrum of AuNPs (black line) and AuNP-antigen-DNA probe (red line). 


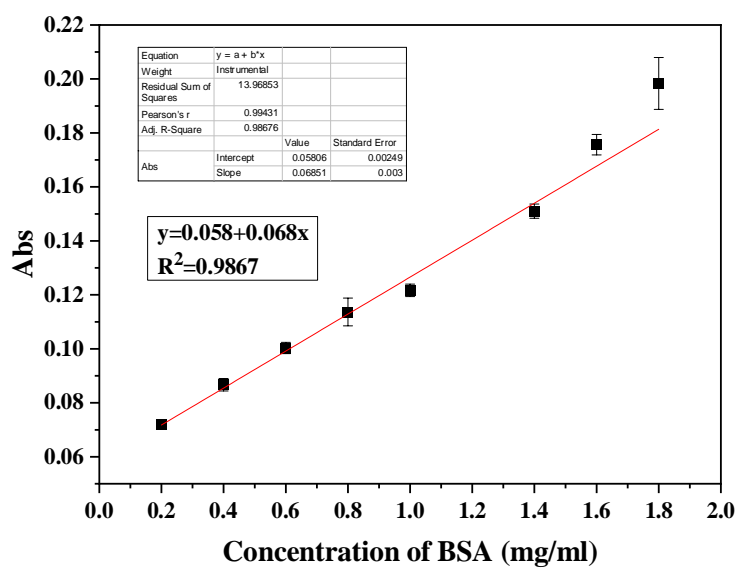

Fig. S4 Standard curve of BCA assay for quantification of protein. The linear range is from 0.2 to $1.8 \mathrm{mg} \mathrm{mL}^{-1}$. 


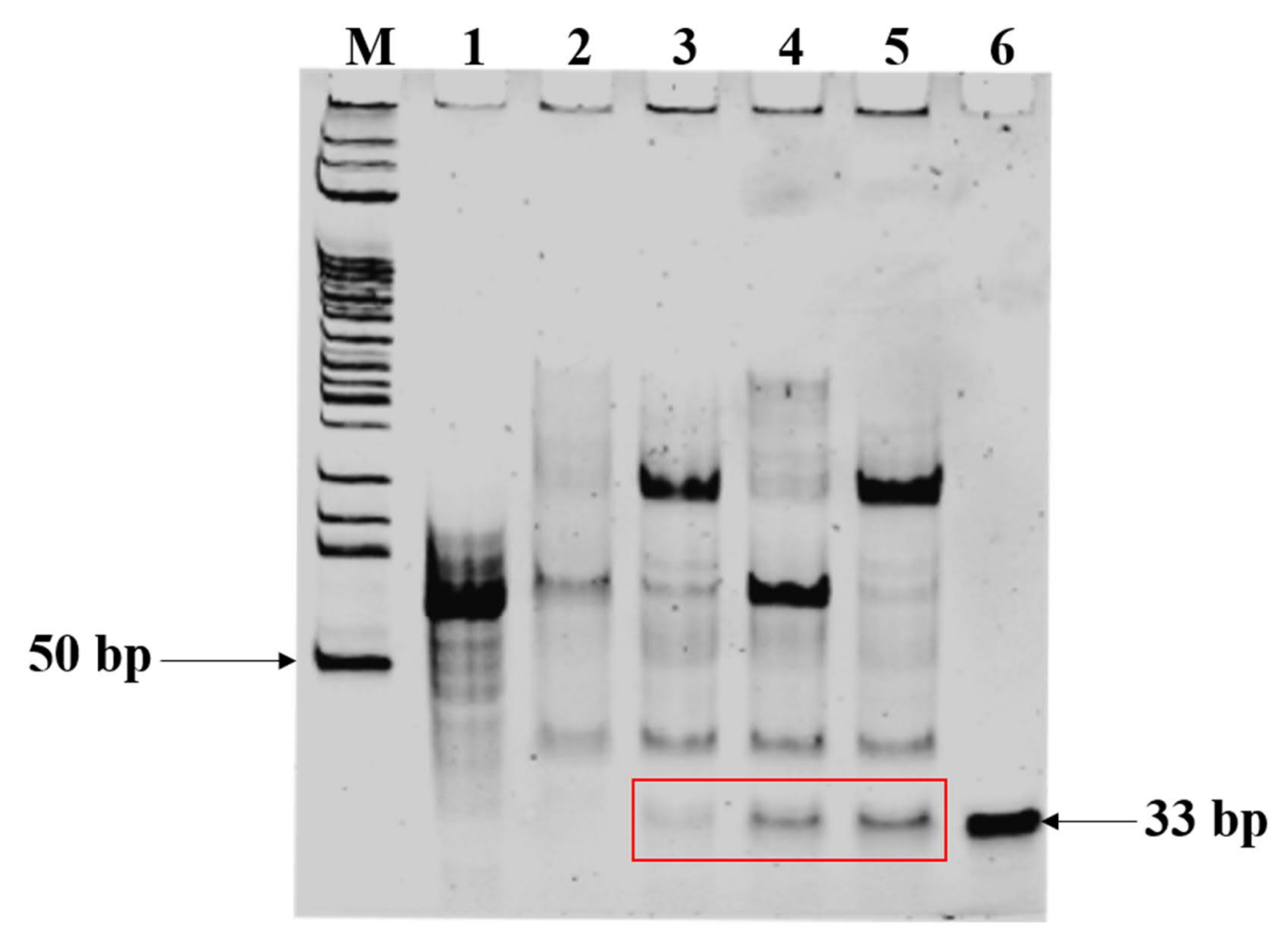

Fig. S5 Gel electrophoresis of DNA products amplified by EXPAR using different concentrations of primer. The lanes from left to right are M: DNA marker; lane 1: $1 \mu \mathrm{M}$ primer (template $10 \mu \mathrm{M}$ ); lane 2: $2 \mu \mathrm{M}$ primer (template $1 \mu \mathrm{M}$ ); lane 3:5 $\mu \mathrm{M}$ primer (template $1 \mu \mathrm{M}$ ); lane 4: $8 \mu \mathrm{M}$ primer (template $1 \mu \mathrm{M}$ ); lane 5: $10 \mu \mathrm{M}$ primer (template 1 $\mu \mathrm{M})$; lane 6: $10 \mu \mathrm{M}$ primer stock solution. All the concentrations mentioned are values of the stock reagent solutions. 


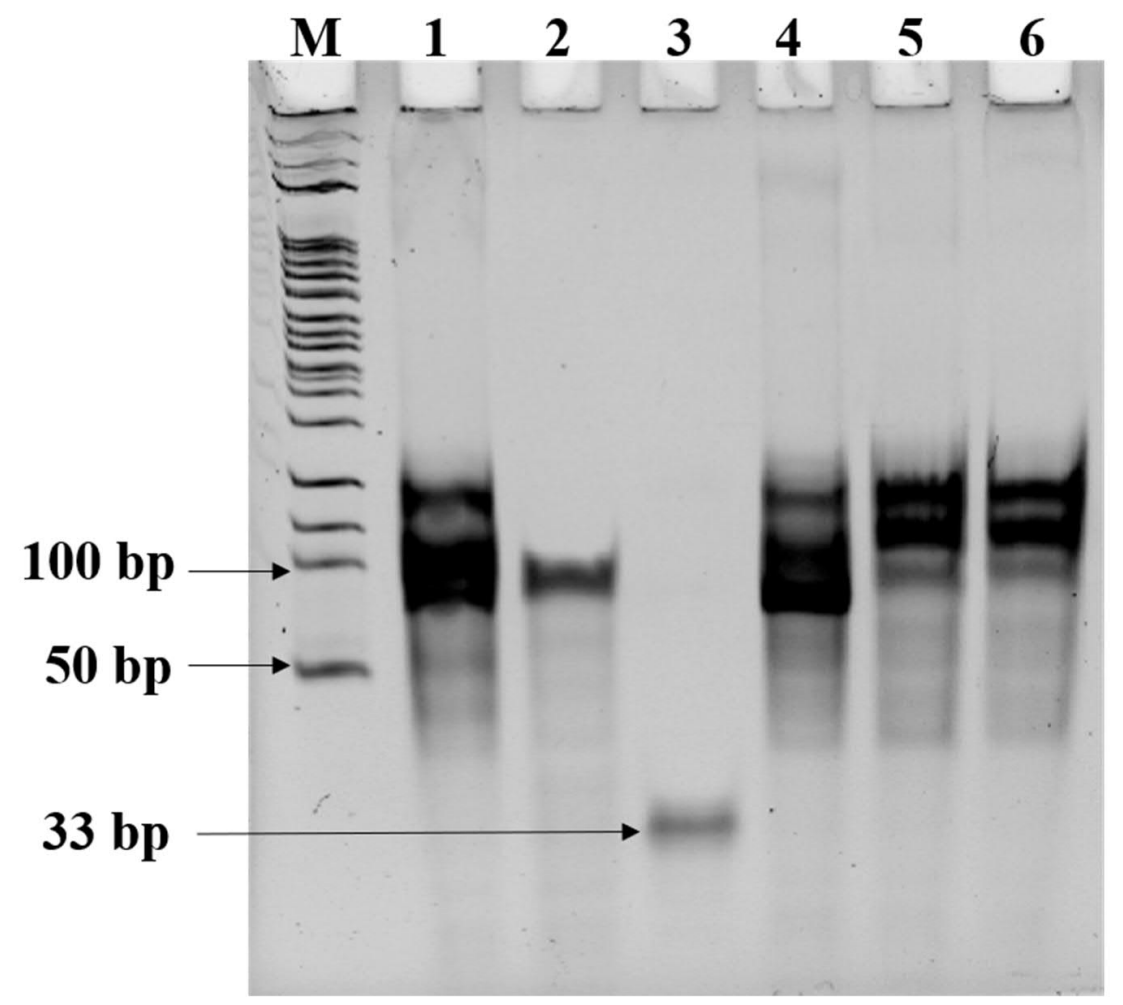

Fig. S6 PAGE (12\%) analysis of EXPAR products after reaction. M: 50 bp marker; Lane 1: reaction mixture without primer; Lane 2: only $10 \mu \mathrm{M}$ template; Lane 3: only $10 \mu \mathrm{M}$ primer; Lane 4: reaction mixture without Nt.BstNBI enzyme; Lane 5: reaction mixture without Vent(exo-) DNA polymerase; Lane 6: reaction mixture without dNTPs. 


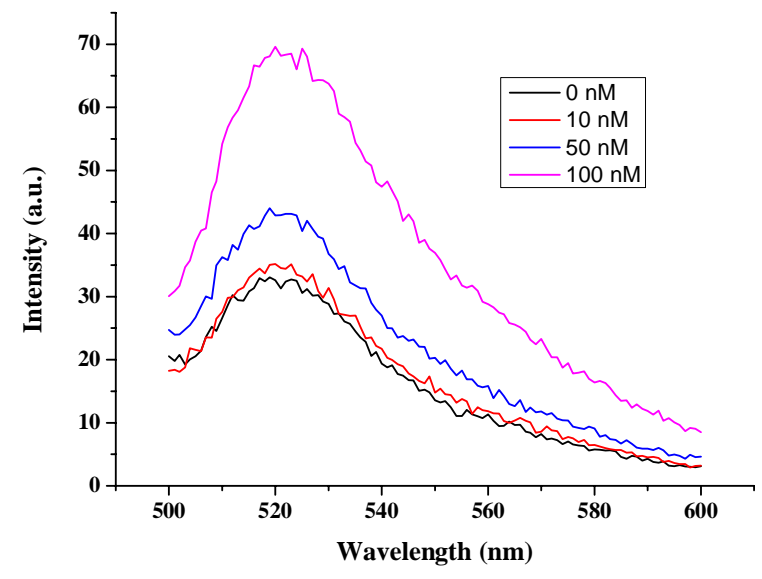

Fig. S7 Fluorescence emissions generated by products of HCR amplification. The HCR products were used to activate Cas12a-gRNA to generate the fluorescence signal. The concentration of $\mathrm{H} 0$ was $0 \mathrm{nM}, 10 \mathrm{nM}, 50 \mathrm{nM}$ and $100 \mathrm{nM}$, respectively. Concentration of $\mathrm{H} 1$ and $\mathrm{H} 2$ were $1 \mu \mathrm{M}$. Concentration of Cas12a and gRNA was $500 \mathrm{nM}$ and $500 \mathrm{nM}$, respectively. 

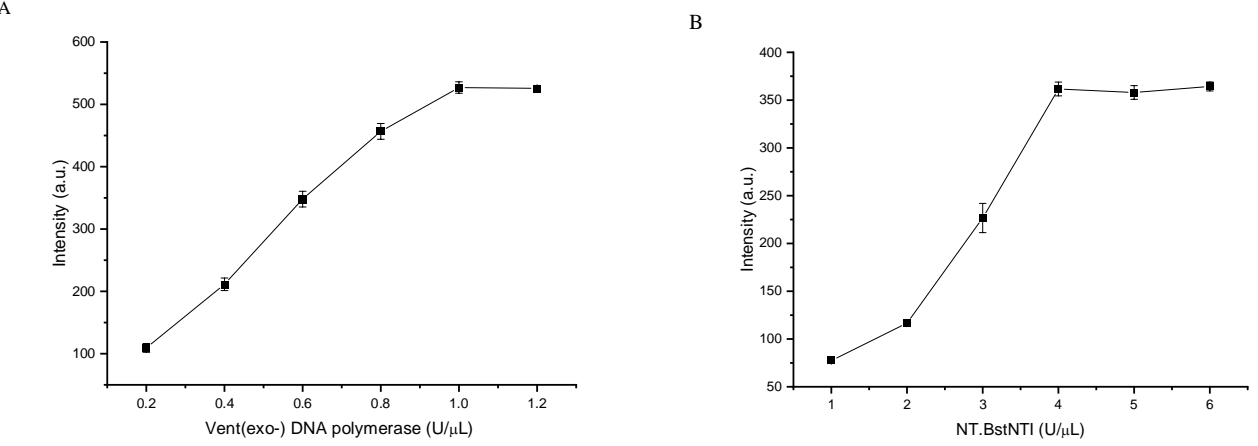

C

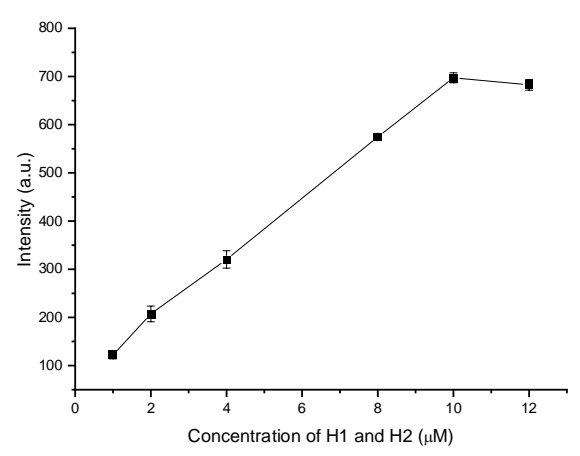

Fig. S8 Optimization of amplification conditions. The change of fluorescence intensity caused by varying concentration of Vent(exo-) DNA polymerase, Nt.BstNBI, H1 and H2 in the stock solutions. (A) Influence of Vent(exo-) DNA polymerase. Concentration of the other stock solutions: Nt.BstNBI (5 U/ $\mu \mathrm{L}) ; \mathrm{H} 1$ and H2 (5 $\mu \mathrm{M})$. (B) Influence of Nt.BstNBI. Concentration of the other stock solutions: Vent(exo-) DNA polymerase $(1 \mathrm{U} / \mu \mathrm{L}) ; \mathrm{H} 1$ and $\mathrm{H} 2(5 \mu \mathrm{M})$. (C) Influence of $\mathrm{H} 1$ and $\mathrm{H} 2$. Concentration of the other stock solutions:

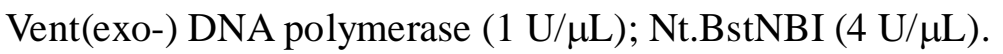


A

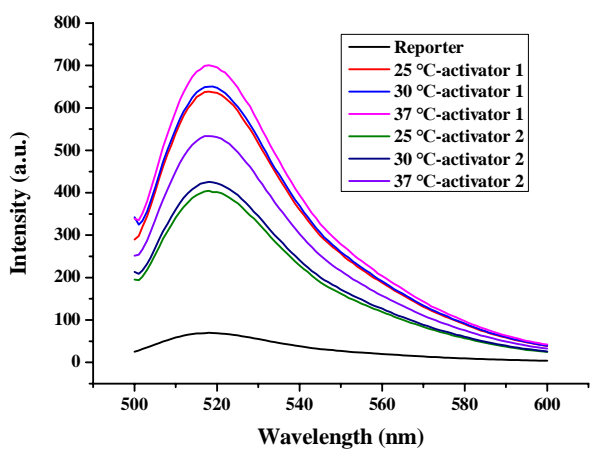

B

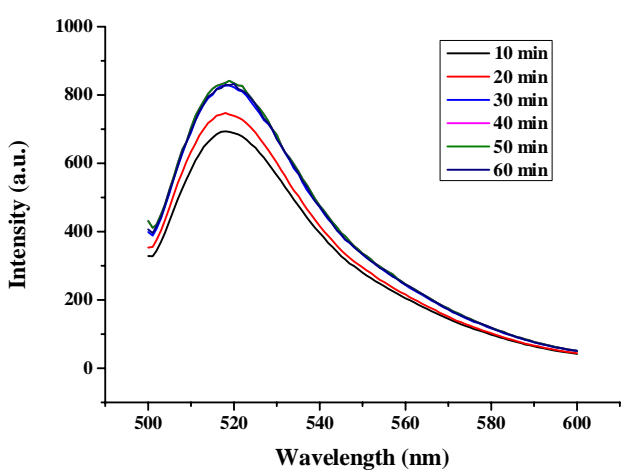

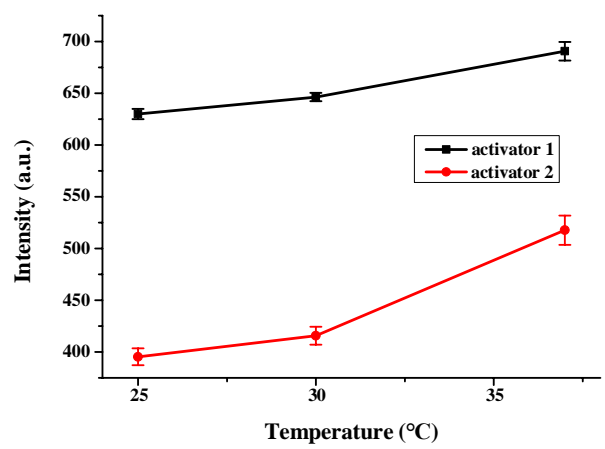

b

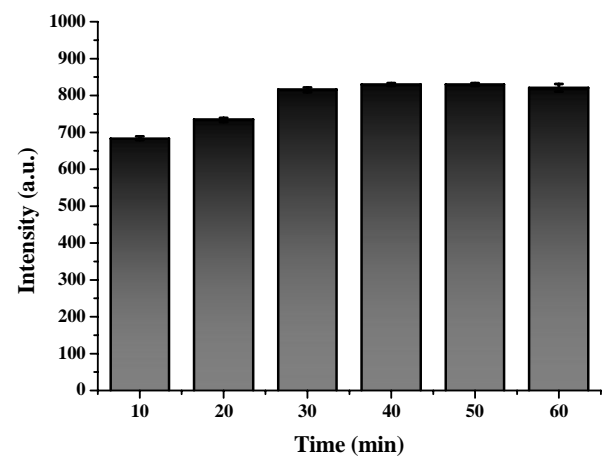

Fig. S9 (A, a) Optimization of Cas12a-gRNA reaction temperature with two different activator concentrations. Activator 1 (10 $\mu \mathrm{M}$ dsDNA); Activator $2(1 \mu \mathrm{M}$ dsDNA). (B, b) Optimization of Cas12a-gRNA reaction time using activator concentration at $10 \mu \mathrm{M}$ and incubation temperature at $37{ }^{\circ} \mathrm{C}$. 


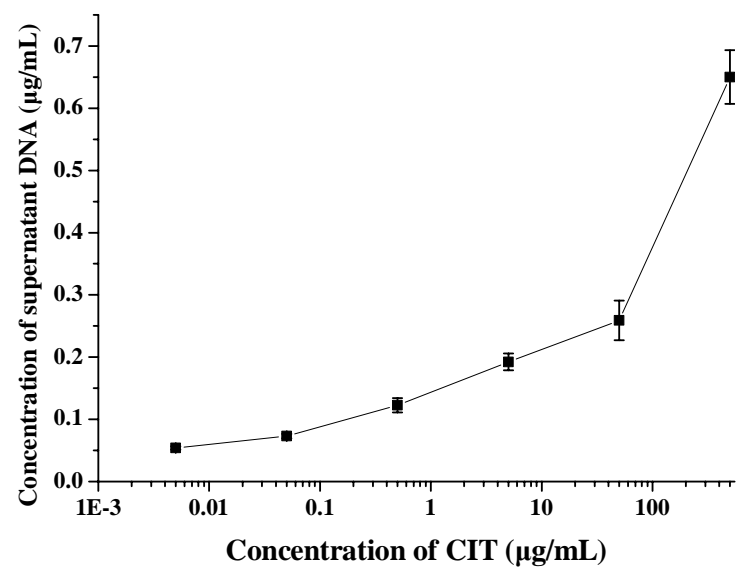

Fig. S10 Quantification of unbound DNA caused by different concentrations of CIT ( 0.005 $\mu \mathrm{g} \mathrm{mL} \mathrm{m}^{-1}-500 \mu \mathrm{g} \mathrm{mL}^{-1}$ ) by measuring UV absorbance of the supernatant after magnetic separation. 